\title{
Comparative effects of exercise on selected cardiorespiratory parameters among young adults from different ethnic groups resident in Nigeria
}

\author{
Alese Ojo Oluwole ${ }^{1}$, Adeosun Olukayode Isaac ${ }^{2}$, Johnson Esther Olubusola ${ }^{3}$, \\ Olukiran Sesan Olaoluwa ${ }^{2, *}$, Alese Margaret Olutayo ${ }^{4}$ \\ ${ }^{1}$ Department of Family Medicine, Ekiti State University Teaching Hospital, Ado-Ekiti, Nigeria \\ ${ }^{2}$ Department of Physiological Sciences, Obafemi Awolowo University, Ile-Ife, Nigeria \\ ${ }^{3}$ Department of Medical Rehabilitation, Obafemi Awolowo University, Ile-Ife, Nigeria \\ ${ }^{4}$ Department of Anatomy, Ekiti State University, Ado-Ekiti, Nigeria
}

\section{Email address:}

alese44@yahoo.com (A. O. Oluwole), iadeosun@fastmail.com (A. O. Isaac), obnik2001@gmail.com (J. E. Olubusola), oolaoluwasesan@gmail.com (O. S. Olaoluwa), babaraalese@yahoo.com (A. M. Olutayo)

\section{To cite this article:}

Alese Ojo Oluwole, Adeosun Olukayode Isaac, Johnson Esther Olubusola, Olukiran Sesan Olaoluwa, Alese Margaret Olutayo. Comparative Effects of Exercise on Selected Cardiorespiratory Parameters among Young Adults from Different Ethnic Groups Resident in Nigeria. American Journal of Clinical and Experimental Medicine. Vol. 2, No. 6, 2014, pp. 123-127. doi: 10.11648/j.ajcem.20140206.12

\begin{abstract}
This study investigated the differences or similarities in the baseline and post exercise cardiorespiratory parameters between young male adults of Igbo and Yoruba. A total of two hundred apparently healthy subjects (100 Yorubas and 100 Igbos) were involved in the study. Subjects were undergraduates who were within the age of 18-30 years. The subjects were asked to sit down for 3 mins and resting cardiorespiratory parameters (pulse rate, blood pressure, forced vital capacity, forced expiratory volume in $1 \mathrm{sec}$ and peak expiratory flow rate) were obtained with the sphygmomanometer and spirometer accordingly. They were then subjected to 3 mins of exercise on a step bench while the metronome was set at 88 and 96 beats per minutes. The results showed a significant decrease in pre exercise pulse rate, systolic blood pressure, diastolic blood pressure of Igbo when compared with Yoruba, but there was no significant differences in post exercise systolic and diastolic blood pressure of Igbo when compared with Yoruba. A significant increase in pre and post exercise forced vital capacity (FVC), forced expiratory volume in 1 second $\left(\mathrm{FEV}_{1}\right)$, and $\mathrm{VO}_{2}$ max was observed in Igbo when compared with Yoruba. The study concluded that there were differences in some cardiorespiratory parameters among male participants of both ethnic groups (Igbo and Yoruba) before and after exercise. The reported data may be useful in interpreting more accurately the significance of increase or decrease in cardiorespiratory response before and after exercise in a subject of a specific ethnic group.
\end{abstract}

Keywords: Exercise, Cardiorespiratory, Adults, Ethnic, Groups

\section{Introduction}

Physical exercise is any bodily activity that enhances or maintains physical fitness and overall health and wellness. Health care providers often call exercise the "miracle" or "wonder" drug - alluding to the wide variety of proven benefits that it provides. Physical inactivity is a serious growing health problem. Regular aerobic physical activity increases exercise capacity and physical fitness, which can lead to many health benefits [1].

Exercise training, the major component of cardiac rehabilitation, reduces the risk factors, improves functional capacity and prognosis, and enhances psychosocial well-being and quality of life in patients suffering from coronary artery disease (CAD) [2]. Exercise training is a powerful secondary preventive measure for those with established Peripheral Arterial Disease (PAD). Studies have confirmed the benefits of exercise training among patients with PAD who do not have claudication [3]. Among individuals with PAD, daily physical activity is reduced approximately $40 \%$ compared to matched healthy controls and the degree of claudication is related to daily physical 
activity within a PAD population [4]. A progressive decline in leisure-time activities of both moderate and high intensities has been identified in individuals with PAD [5]. Furthermore, a relation appears to exist between free-living physical activity and microcirculation in the calf muscle [6]. The natural progression of PAD has been assessed and determined to be inversely related to self-reported physical activity and calf blood flow [7]. Both aerobic and progressive resistance exercises yield important reductions in systolic and diastolic blood pressure (BP) in adult humans, although the evidence for aerobic exercise is more convincing.

Cardiovascular disease (CVD) account for the majority of premature morbidity and mortality in the developed world. The influence of physical activity on the prevention and treatment of cardiovascular diseases is therefore of great importance [8]. In considering the effects of physical activity on cardiovascular health, one must address not only its influence on the development of symptomatic disease (e.g., heart attack and stroke) but also the influence on risk factors that are known to contribute to the development of symptomatic disease and are often indicative of sub-clinical asymptomatic vascular pathology. In turn, both physical inactivity and poor cardiorespiratory fitness are major risk factors for cardiovascular diseases. Few studies conducted in the United States have had an adequate sample size and clinical outcomes to evaluate the association between physical activity and CVD clinical events in race or ethnic groups other than non-Hispanic whites. According to Folsom [9], in a follow up study of over 7000 black and white men and women age 46years to 65 years the influence of physical activity on the development of hypertension and clinical cardiovascular disease events was much stronger and more consistent in white than in blacks. This lack of association in blacks may be due to the limited number of blacks reporting vigorous physical activity (5\% in black men versus $15 \%$ in white men). However, outside the United States, where the relation between physical activity level and CVD clinical events had been evaluated in other race and ethnic populations, there is no indication that the favorable association frequently reported for non-Hispanic white men does not occur in other race and ethnic populations. For example, physically active Japanese men living in Japan [10], and older Japanese men living in Hawaii [11] had lower CVD mortality rates than the least active Japanese men. Similar results have been reported for Chinese men living in Hong Kong [12].

Most of the reported studies of exercise on cardiorespiratory parameters were carried out on white men. There are limited data on the variation of the effects of exercise on cardiorespiratory parameters that is ethnic based among young adults in sub-Sahara region of Africa. Therefore, this study is aimed at assessing the comparative effects of exercise on selected cardiorespiratory parameters among young male adults from different ethnic groups in Nigeria with case study from Ado-Ekiti.

\section{Materials and Methods}

\subsection{Subjects}

Two hundred apparently healthy subjects (100 Yorubas and 100 Igbos) were used for this study. Subjects were undergraduate students from Ekiti State University (EKSU), within ages 18-30 years. The Igbo subjects were born and raised in Igbo land but were resident in Ado-Ekiti for studies. Ethical clearance was obtained from the research and ethics committee of Ekiti State University Teaching Hospital, Ado-Ekiti. All subjects were aware of the risk and requirement of participating in the study and all signed a written informed consent form prior to the study. Also, subjects filled health status questionnaire to know if they were qualified for the study.

With the use of health status questionnaire and physical examination, individuals with underlying heart, lungs and other systemic diseases were excluded; alcoholics, athletes, cigarette smokers and chronic coffee users were also excluded.

\subsection{Anthropometric Measurements}

Weight and height were measured using portable body weighing scale and wall mounted stadiometer respectively. The body mass index (BMI) was then computed using a standard formula $\left[\mathrm{BMI}=\right.$ weight $\left.(\mathrm{kg}) / \operatorname{height}^{2}\left(\mathrm{~m}^{2}\right)\right]$.

\subsection{Cardiovascular Parameters}

The pulse rate and blood pressure were measured using a digital sphygmomanometer (OMRON M2 $2^{\mathrm{TM}}$ ) with the subjects in sitting position and cuff tied round the arm at $4 \mathrm{~cm}$ above the cubital fossa.

\subsection{Metronome}

$\operatorname{Korg}^{\mathrm{TM}}$ solo metronome M-1 was used to determine the pace at which the subject made contact with the bench and the ground in a minute with its rhythm.

\subsection{Respiratory Parameters}

The forced vital capacity, forced expiratory volume in one second and peak expiratory flow rate were measured using a CONTEC $^{\mathrm{TM}}$ electronic portable hand held spirometer SP10 Model. The American Thoracic Society Standard [13] was used to get the correct interpretation. The spirometer was set at the age, sex and height of each subject.

\subsection{Exercise Program}

Subjects were asked to sit down for three minutes and the resting cardiorespiratory parameters (pulse rate, blood pressure, forced vital capacity, forced expiratory volume in 1 sec and peak expiratory flow rate) were measured. Participants were then subjected to 3 mins of exercise on a step bench; the metronome was set at 96 beats per minutes to allow the subjects make contact with a foot on each beep in an up-up-down-down manner and thus $24 \mathrm{steps} / \mathrm{min}$ for each 
participant. All the cardiorespiratory parameters were measured and the rate pressure product and $\mathrm{VO}_{2} \max$ were calculated.

\subsection{Statistical Analysis}

Data were analyzed using SPSS Windows Version 17.0 (SPSS Inc, IBM, UK). Descriptive statistics of mean standard deviation and percentage were used to summarize the data obtained. Two-sided P values were calculated using the Paired sample $\mathrm{T}$ test for observed variables. $\mathrm{P}$ values $<0.05$ were considered statistically significant.

\section{Results}

\subsection{Baseline Characteristics of Subjects}

As observed in Table 1, there were significant decreases in baseline pulse rate, systolic blood pressure and diastolic blood pressure of Igbo when compared with Yoruba. However, a significant increase in forced vital capacity (FVC), forced expiratory volume in 1 second $\left(\mathrm{FEV}_{1}\right)$, peak expiratory flow rate (PEFR) were observed in Igbo when compared with
Yoruba.

Table 1. Comparison of baseline parameters of Igbo and Yoruba male participants.

\begin{tabular}{lllll}
\hline Parameter & Yoruba $( \pm$ SD $)$ & Igbo $( \pm$ SD $)$ & t-value & P-value \\
\hline PR(b/min) & $72.3 \pm 11.95$ & $67.72 \pm 9.02$ & 2.16 & $0.036^{*}$ \\
SBP $(m m H g)$ & $132.34 \pm 14.12$ & $121.68 \pm 12.35$ & 4.55 & $0.01^{*}$ \\
DBP(mmHg) & $7.018 \pm 8.97$ & $65.96 \pm 10.87$ & 2.26 & $0.03^{*}$ \\
FVC(L) & $2.455 \pm 0.50$ & $2.857 \pm 0.67$ & -3.24 & $0.01^{*}$ \\
FEV $($ L $)$ & $2.298 \pm 0.47$ & $2.569 \pm 0.57$ & -2.67 & $0.01^{*}$ \\
PEF $(\mathrm{L} / \mathrm{s})$ & $5.4806 \pm 2.04$ & $6.4942 \pm 1.42$ & -3.18 & $0.01^{*}$ \\
\hline
\end{tabular}

* = Significance at $\mathrm{p}<0.05$. PR- Pulse Rate, SBP- Systolic Blood Pressure DBP - Diastolic Blood pressure, FVC- Forced Vital capacity, $\mathrm{FEV}_{1}$ - Forced Expiratory Volume in one second, PEF - Peak Expiratory Flow, $\mathrm{VO}_{2} \max -$ Maximum Oxygen Consumption, RPP - Rate Pressure Product

\subsection{Post-Exercise Test Characteristics of Subjects}

There was a significant decrease in post exercise pulse rate of Igbo when compared with Yoruba. However, there were no significant differences in post exercise systolic blood pressure and diastolic blood pressure of Igbo when compared with Yoruba male participants (Table 2).

Table 2. Comparison of post exercise parameters of Igbo and Yoruba male participants.

\begin{tabular}{|c|c|c|c|c|}
\hline Parameter & $\operatorname{Yoruba}( \pm$ SD $)$ & $\operatorname{Igbo}( \pm \mathrm{SD})$ & t-value & P-value \\
\hline $\mathrm{PR}(\mathrm{b} / \mathrm{min})$ & $96.78 \pm 14.74$ & $89.52 \pm 15.82$ & 2.37 & $0.02^{*}$ \\
\hline $\mathrm{SBP}(\mathrm{mmHg})$ & $153.68 \pm 17.31$ & $148.08 \pm 18.82$ & 1.68 & 0.10 \\
\hline $\mathrm{DBP}(\mathrm{mmHg})$ & $73.14 \pm 8.21$ & $68.96 \pm 13.68$ & 1.82 & 0.08 \\
\hline $\mathrm{FVC}(\mathrm{L})$ & $2.46 \pm 0.69$ & $2.76 \pm 0.66$ & -2.16 & $0.04^{*}$ \\
\hline $\mathrm{FEV}_{1}(\mathrm{~L})$ & $2.36 \pm 0.61$ & $2.61 \pm 0.58$ & -2.09 & $0.042^{*}$ \\
\hline $\mathrm{PEF}(\mathrm{L} / \mathrm{s})$ & $6.41 \pm 1.88$ & $6.35 \pm 1.73$ & 0.17 & 0.87 \\
\hline $\mathrm{VO}_{2} \max (\mathrm{ml} / \mathrm{kg} / \mathrm{min})$ & $69.46 \pm 6.45$ & $73.72 \pm 6.65$ & -3.41 & $0.01^{*}$ \\
\hline $\mathrm{RPP}(\mathrm{b} / \mathrm{pm} \times \mathrm{mmHg})$ & $15106.98 \pm 4367.62$ & $13498.74 \pm 2970.22$ & 2.13 & $0.04^{*}$ \\
\hline
\end{tabular}

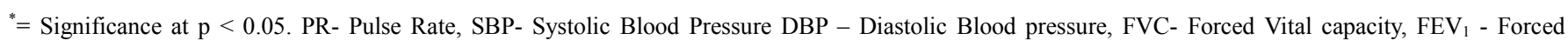

Expiratory Volume in one second, PEF- Peak Expiratory Flow, $\mathrm{VO}_{2} \max -$ Maximum Oxygen Consumption, RPP - Rate Pressure Product

A significant increase in the post exercise $\mathrm{FVC}$ and $\mathrm{FEV}_{1}$ were observed in Igbo when compared with Yoruba male participants. Similarly, a significant increase in the $\mathrm{VO}_{2} \max$ was observed in Igbo when compared with Yoruba male participants. Igbo male participants showed a lower post exercise peak expiratory flow rate than Yoruba male participants after exercise, but this was not statistically significant. Igbo male participants rate pressure product was significantly lower than that of the Yoruba.

\subsection{Anthropometric Measurements of Subjects}

Table 3. Comparison of anthropometric measurements and age of Igbo and Yoruba male participants.

\begin{tabular}{lllll}
\hline Parameters & Yoruba $( \pm$ SD) & Igbo $( \pm$ SD) & t-value & P-value \\
\hline Weight $(\mathrm{kg})$ & $67.8 \pm 8.66$ & $67.32 \pm 8.77$ & 0.31 & 0.76 \\
Height $(\mathrm{m})$ & $1.74 \pm 0.07$ & $1.73 \pm 0.07$ & 0.63 & 0.54 \\
BSA $\left(\mathrm{m}^{2}\right)$ & $1.8 \pm 0.13$ & $1.8 \pm 0.13$ & 0.45 & 0.66 \\
Age $(Y r s)$ & $26.74 \pm 2.36$ & $26.86 \pm 2.08$ & -0.28 & 0.79 \\
BMI $\left(\mathrm{kg} / \mathrm{m}^{2}\right)$ & $22.25 \pm 2.66$ & $22.21 \pm 2.16$ & 0.10 & 0.92 \\
\hline
\end{tabular}

BSA- Body Surface Area, BMI-Basal Metabolic Index.

As shown in Table 3, there were no significant differences in the weight, height, age and body mass index (BMI) of Igbo when compared with Yoruba male participants.

\section{Discussion}

A sound heart, healthy lungs and a well-developed physique are assets for accomplishment of a full and satisfying life. Exercise has been considered the key to cardiorespiratory fitness and this is dependent on the pattern and level.

Results indicate a significantly higher pulse rate, systolic blood pressure, diastolic blood pressure of Yoruba when compared with Igbo before exercise. Differences in autonomic nervous system activity might help explain the differences observed. Studies [14,15] have shown that a rise in SBP and DBP is mainly due to increase in cardiac output and venous return and reflects the level of sympathetic and parasympathetic drive. Increase in cardiac output is a function of increase in heart rate (HR). Changes in blood pressure are usually mediated by the baroreflex mechanism via HR changes [16]. This baroreflex mediated response of $\mathrm{HR}$ to changes in arterial blood pressure indicates the 
capacity of reflex cardiac autonomic modulation [17]. A progressive increase in HR has been reported to be due to increase in sympathetic activity and a decrease in parasympathetic activity [18]. The significant decrease in post exercise pulse rate that was observed in Igbo when compared with Yoruba could be attributed to cardiovagal baroreflex sensitivity [19,20], causing increase sympatho-inhibition and vagal activation of the heart and arterial vasculature, thereby leading to decrease in heart rate.

Maximal oxygen uptake or consumption $\left(\mathrm{VO}_{2} \mathrm{max}\right)$ is the maximum capacity of an individual's body to transport and use oxygen during incremental exercise [21] which reflects the physical fitness of an individual. The significant increase in $\mathrm{VO}_{2}$ max that was observed in Igbo when compared with Yoruba may have resulted from increase in mitochondrial muscle oxidative capacity and oxygen delivery capabilities as determined by sub maximal oxygen pulse. Coetzer et al. [22] suggested that higher $\mathrm{VO}_{2}$ max can be explained by a higher percentage of fiber type I and IIa and higher resistance to fatigue. It has been previously reported that lower haemoglobin was associated with a lower $\mathrm{Vo}_{2} \max$ [23]. Another possible factor, not examined in the present study that may contribute to differences in $\mathrm{VO}_{2}$ max could be differences in haemoglobin flow rate or genetic traits. Both of these factors could have contributed to comparatively lower arterial $\mathrm{O}_{2}$ content and ultimately lower tissue respiration during maximal exercise in Yoruba group. This needs to be further investigated.

The pre and post exercise forced vital capacity (FVC), forced expiratory volume in one second $\left(\mathrm{FEV}_{1}\right)$ were significantly higher in male Igbo participants than Yoruba males. This may have resulted from increased development of respiratory musculature incidental to the physical training whose intensity is a strong determining factor. The enhanced respiratory functional capacity however does not lead to an enhancement of their basal metabolic functions.

\section{Conclusion}

In conclusion, this work has established differences in some cardiorespiratory parameters among male participants of both ethnic groups (Igbo and Yoruba) before and after exercise. The anthropometric parameters (weight and height) and age of the participants could not account for the differences observed. The reported data could be used by clinicians to interpret more accurately the significance of increase or decrease in cardiorespiratory response before and after exercise in a subject of a specific ethnic group.

\section{References}

[1] G. De Backer, E. Ambrosioni, K. Borch-Johnsen, C. Brotons, R. Cifkova, J. Dallongeville J, S. Ebrahim, O. Faergeman, I. Graham, G. Mancia, V. Manger Cats, K. Orth-Gomér, J.Perk , K. Pyörälä , JL. Rodicio , S. Sans, V. Sansoy, U. Sechtem, S. Silber, T. Thomsen, and D. Wood. European Guidelines on cardiovascular disease prevention in clinical practice. Third Joint Task Force of European and Other Societies on Cardiovascular Disease Prevention in Clinical Practice. European Heart Journal, 24(17): 1601-10, 2003.

[2] A.S. Leon, B.A. Franklin, F. Costa, et al. Cardiac rehabilitation and secondary prevention of coronary artery disease. Circulation, 111:369-76, 2005.

[3] M. Naomi, M.D. Hamburg, J. Gary, M.D. Balady. Exercise rehabilitation in peripheral artery disease. Circulation, 123: 87-97, 2011.

[4] D.J. Sieminski and A.W. Gardner. The relationship between free-living daily physical activity and the severity of peripheral arterial occlusive disease. Vascular Medicine, 2(4):286-91, 1997.

[5] A.W. Gardner and R.J. Clancy. The relationship between ankle-brachial index and leisure-time physical activity in patients with intermittent claudication. Angiology 57(5): 539-45, 2006.

[6] A.W. Gardner, C.J. Womack, D.J. Sieminski, P.S. Montgomery, L.A. Killewich, and Fonong T. Relationship between free-living daily physical activity and ambulatory measures in older claudicants. Angiology 49(5):327-37, 1998.

[7] A.W. Gardner, P.S. Montgomery, and L.A. Killewich. Natural history of physical function in older men with intermittent claudication. Journal of Vascular Surgery. 40(1):73-8, 2004.

[8] National Institute on Aging. Global Health and Aging. World Health Organization. 11 (7737); 1-28, 2011.

[9] A.R. Folsom, D.K. Arnett, R.G. Hutchinson, F. Liao, L..X. Clegg, and L.S. Cooper. Physical activity and incidence of coronary heart disease in middle-aged women and men. Medicine and Science in Sports and Exercise. 29(7): 901-9, 1997.

[10] H, Noda, H, Iso, H, Toyoshima, C, Date, A, Yamamoto, S, Kikuchi, A, Koizumi, T, Kondo, Y, Watanabe, and Y, Wada. Walking and sports participation and mortality from coronary heart disease and stroke. Journal of the American College of Cardiology. 46(9):1761-7, 2005.

[11] A.A, Hakim, H, Petrovitch, C.M, Burchfiel, G.W. Ross, B.L.. Rodriguez, L.R. White, K. Yano, J.D.Curb, and R.D. Abbott (1998). Effects of walking on mortality among nonsmoking retired men. New England Journal of Medicine. 338(2): 94-9, 1998.

[12] T.H. Lam, S.Y. Ho, A.J. Hedley, K.H. Mak, G.M. Leung. Leisure time physical activity and mortality in Hong Kong: case-control study of all adult deaths in 1998. Annals of Epidemiology. 14(6):391-8, 2004.

[13] American Thoracic Society (Statement). Standardization of spirometry, Update. American Thoracic Society." American Journal of Respiratory and Critical Care Medicine, 152 (3): 1107-36, 1994.

[14] J.A. Laukkanen, S. Kurl , R. Salonen, T.A Lakka, R. Rauramaa, and J.T. Salonen. Systolic blood pressure during recovery from exercise and the risk of acute myocardial infarction in middle aged men. Hypertension, 44:820-825, 2004.

[15] W.F. Ganong . Review of Medical Physiology. 23rd ed. Mc Graw Hill, New York, pp 656, 2010. 
[16] T.C. Fitpro. Blood pressure and exercise. American fitness Professionals and Associates 1998; Retrieved on 28 November, 2006 from http://www.afpafitness.com/articl/article - and newsletter.

[17] H.V. Huikuri, S.M. Pikkujamsa , K. E. Airaksinen, M.J. Ikaheimo, A.O. Rantala, and, H. Kaum, et al. Sex related differences in autonomic modulation of heart rate in middle-aged subjects. Circulation, 94:122-125, 1996.

[18] G.D. Curfman and L.D. Hillis. A new look at cardiac exercise testing. N Engl J Med 348: 775-776, 2003.

[19] M. Javorka, I. Zila, T. Balharek, K. Javorka. Heart rate recovery after exercise; relations to heart rate variability and complexity. Braz J Med Biol Res, 35:991-1000, 2002.

[20] N. Du, S. Bai, K. Oguri ,Y. Kato, I. Matsumoto, and H. Kawase, et al. Heart rate recovery after exercise and neural regulation of heart rate variability in $30-40$ years old female marathon runners. J Sports Sci Med, 4:9-17, 2005.

[21] E.M Dlugosz, M.A. Chappell, T.H. Meek, P. Szafranska, K. Zub, M. Konarzewski, J.H. Jones, J.E.P.W. Bicudo, V. Careau, Garland Jr. Phylogenetic analysis of mammalian maximal oxygen consumption during exercise. Journal of Experimental Biology 216:4712-4721, 2013.

[22] P. Coetzer, T.D. Noakes, B. Sanders, M.I. Lambert, et al. Superior fatigue resistance of elite black South African distance runners. Journal of Applied Physiology, 75, 1822-1827, 1993.

[23] J.L. Andreacci, R.J. Robertson, J.J. Dube, D.J. Aaron, C..B. Dixon, and S. A. Arslanian. Comparison of maximal oxygen consumption between obese black and white adolescents. Pediatric Research. 58(3): 478-2, 2005. 